\title{
Long-term suppression of postprandial hyperglycaemia with acarbose retards the development of neuropathies in the $\mathrm{BB} / \mathrm{W}$-rat
}

\author{
A. A.F. Sima ${ }^{1}$ and S. Chakrabarti ${ }^{2}$ \\ Departments of Pathology and Internal Medicine and Michigan Diabetes Research and Training Center, University of Michigan, \\ Ann Arbor, Michigan, USA, and \\ 2 Department of Pathology, University of Manitoba, Winnipeg, Canada
}

\begin{abstract}
Summary. The effect of the $\alpha$-glucosidase inhibitor acarbose on postprandial hyperglycaemia was explored in the spontaneously diabetic BB/W-rat. Acarbose-treatment $(5 \mathrm{mg} \cdot \mathrm{kg}$ body weight ${ }^{-1} \cdot$ day $^{-1}$ ) of diabetic $\mathrm{BB} / \mathrm{W}$-rats maintained on small doses of insulin, was associated with a $40 \%$ reduction in the 24-h glucose area compared to non-treated diabetic rats. Over a 4 month treatment period this reduction in cumulative hyperglycaemia resulted in a complete prevention of autonomic polyneuropathy as indicated by R-BAR values. The development of somatic polyneuropathy in the BB/Wrat was significantly attenuated by acarbose treatment with a partial prevention of the characteristic nerve conduction
\end{abstract}

velocity slowing during the first 3 months of diabetes, but no longer at 4 months. Characteristic structural abnormalities associated with diabetes in this model, such as axonal atrophy and axo-glial dysjunction, were significantly but only partially prevented in rats treated with acarbose for a diabetes duration of 4 months. These data suggest that postprandial lowering of hyperglycaemia resulting in a decrease in cumulative hyperglycaemia retards the development of diabetic polyneuropathies in the $\mathrm{BB} / \mathrm{W}$-rat.

Key words: Postprandial hyperglycaemia, autonomic neuropathy, somatic neuropathy, BB/W-rat.
The diabetic polyneuropathies are common secondary complications of diabetes mellitus and contribute significantly to the morbidity and mortality associated with this disease [1-4]. The pathogenesis of diabetic polyneuropathies is a topic of lively controversy, although metabolic abnormalities secondary to hyperglycaemia, microvascular abnormalities as well as independent predisposing genetic factors are probably the major mechanisms involved in the genesis of the neuropathic complications [5-9]. Epidemiological studies associate the incidence of clinically overt neuropathy with duration of diabetes and glycaemic control, suggesting that cumulative hyperglycaemia may be a major contributing factor $[3,10,11]$. Although attractive, this hypothesis has never been tested under strict experimental conditions.

The spontaneously diabetic BB/W-rat has emerged as a valuable experimental model with which to explore the pathogenesis and natural history of diabetic neuropathy, since it develops diabetic neuropathies that closely mimic those seen in man [2,12-14].

As in human diabetic subjects the BB/W-rat develops autonomic neuropathy with a progressive decrease in heart beat variability reflecting vagal neuropathy $[15,16]$. The somatic neuropathy is characterized by a progressive decrease in nerve conduction velocity that precedes and accompanies the development of structural abnormalities affecting the node of Ranvier and the internodal axon of myelinated fibres $[12,13,17]$, analogous to the neuroanatomical lesions seen in diabetic neuropathic patients [18-20].

In order to explore the discriminative effect of the degree of hyperglycaemia on the development of somatic and autonomic polyneuropathies in the $\mathrm{BB} / \mathrm{W}$-rat, diabetic animals were given the $\alpha$-glucosidase inhibitor acarbose (BAY g 5421; Miles Inc., West Haven, Conn., USA) from onset of diabetes for a period of 4 months. This compound is a potent competitive inhibitor of small intestine $\alpha$-glucosidase and significantly suppresses postprandial increases in blood glucose and insulin responses in the rat and man [21-24].

In this report we demonstrate that lowering of postprandial hyperglycaemia resulting in a decreased 24 -h glucose area is associated with attenuated developments of autonomic and somatic polyneuropathies in the BB/W-rat.

\section{Materials and methods}

Animals

Twelve pre-diabetic male BB/W-rats and six age-matched nondiabetes-prone male $\mathrm{BB} / \mathrm{W}$-rats were obtained from the National 
Table 1. Clinical data in control, diabetic and acarbose-treated diabetic BB/W-rats

\begin{tabular}{llcl}
\hline & $\begin{array}{l}\text { Body weight } \\
(\mathrm{g})\end{array}$ & $\begin{array}{l}\text { Blood glucose } \\
(\mathrm{mmol} / \mathrm{l})\end{array}$ & $\begin{array}{l}\text { Glycated Hb } \\
(\%)\end{array}$ \\
\hline $\begin{array}{l}\text { Control rats } \\
(n=6)\end{array}$ & $457 \pm 7$ & $4.7 \pm 0.6$ & $4.5 \pm 0.4$ \\
$\begin{array}{l}\text { Diabetic rats } \\
(n=6)\end{array}$ & $365 \pm 6^{\mathrm{a}}$ & $17.8 \pm 3.0^{\mathrm{a}}$ & $9.8 \pm 0.6^{\mathrm{a}}$ \\
$\begin{array}{l}\text { Acarbose-treated } \\
\text { Diabetic rats } \\
(n=6)\end{array}$ & $383 \pm 13^{\mathrm{a}}$ & $13.8 \pm 0.6^{\mathrm{a}}$ & $7.2 \pm 0.3^{\mathrm{b}}$ \\
\hline${ }^{\mathrm{a}} p<0.001$ vs control rats; ${ }^{\mathrm{b}} p<0.05$ diabetic rats &
\end{tabular}

Institutes of Health's Colony at the University of Massachusetts, Worcester, Massachusetts, USA. At the time of diabetes detection, identified by glucosuria (Test Tape; Eli Lilly Canada Inc., Toronto, Ontario, Canada), diabetic rats were started on small daily doses (0.5-3.0 U/day) of protamine zinc insulin (PZI) (Connaught-Novo Inc., Toronto, Ontario, Canada), in order to prevent ketoacidosis from occurring. The insulin doses were titrated daily based on urine volume and glucose content. Six diabetic and six non-diabetic control rats were given free access to rat chow (Lab Blox F-6; Wayne Animal Diets, Winnipeg, Manitoba, Canada) and water. The remaining six diabetic rats were given rat chow ad-mixed with $20 \mathrm{mg}$ acarbose $100 \mathrm{~g}$ chow (BAY g 5421) equivalent to a daily dose of no less than $5 \mathrm{mg} / \mathrm{kg}$ body weight. All animals were maintained in airfiltered metabolic cages with a 12 -h light cycle.

\section{Clinical monitoring}

Body weight, urine volume, and glucosuria were monitored daily. Blood glucose was measured weekly in tail-vein blood samples by Ames Eyetone (Miles Laboratory Ltd., Rexdale, Ontario, Canada). In addition, non-treated and acarbose-treated diabetic rats were monitored with respect to blood glucose levels at $2-\mathrm{h}$ intervals, for four separate $24 \mathrm{~h}$ cycles, one during each month of the 4 month treatment protocol. Glycated haemoglobin was measured in tailvein blood samples every month using an affinity chromatography test kit (Glyco-Test, Pierce Chemical Co., Rockford, Ill., USA).

\section{$R$-BAR monitoring}

Animals were anaesthetized with diethyl ether (Fisher Scientific Co., Fair Lawn, NJ, USA) and simultaneous analog movement, ECG and respiration signals were obtained as previously described in detail $[15,25]$. The computed $R$-statistics (R-BAR) defined as the vector mean of the $R$ spikes wrapped around a circle, the circumference of which represents the time of one respiration. Each R$B A R$ value represents the mean of R-BAR's obtained during a 5 min movement free recording. R-BAR data were obtained monthly during the experiment.

\section{Nerve conduction velocity}

Animals were anaesthetized with diethyl ether. Nerve conduction velocity (NCV) was then determined non-invasively in the sciatictibial conducting system in a temperature-controlled environment as previously described in detail $[13,17]$. The left sciatic nerve was stimulated at the sciatic notch and at the ankle with bipolar electrodes using supramaximal stimuli of $8 \mathrm{~V}$. Evoked muscle potentials were collected from the first interosseous space of the hind paw and displayed on an oscilloscope. NCV was calculated by subtracting the distal from the proximal latency, measured from stimulus artifact to take-off of the evoked potential, and divided by the distance between the two stimulating electrodes.

\section{Tissue collection}

Animals were anaesthetized with sodium pentobarbitol $(50 \mathrm{mg} / \mathrm{kg}$ body weight). The sural nerve of the right side was fixed in situ for 10 min with a cacodylate-buffered ( $\mathrm{pH} 7.40) 2.5 \%$ glutaraldehyde fixative. The sural nerve was then carefully dissected and left in the same fixative for $4 \mathrm{~h}$ at $4^{\circ} \mathrm{C}$ and post-fixed in cacodylate-buffered $1 \%$ osmic tetroxide ( $\mathrm{pH} 7.4$ ) for $2 \mathrm{~h}$. The distal portion of the nerve sample was dehydrated in ethanol and embedded in Epon. Ultrathin cross- and longitudinal sections were stained with aqueous uranyl acetate and lead citrate for electron microscopic examination. The proximal portion of the nerve was used for teased fibre preparations in unpolymerized Epon.

\section{Structural examinations}

Myelinated fibre size, fibre density and fibre occupancy were calculated from semi-thin $(0.5 \mu \mathrm{m})$ toluidine blue-stained sections of the entire sural nerve. The cross-sectional area of each myelinated fibre was digitized and the endoneurial area planimetered with the aid of a Hewlett-Packard computerized digitizer as previously described in detail [13].

The extent of axonal atrophy was assessed by scoring of teased fibres displaying excessive myelin wrinkling and expressed as a percentage of examined fibres as previously described [18]. The degree of axonal atrophy was assessed independently by calculating the axon/myelin ratio of a mean of $92 \pm 6$ systematic randomly chosen fibres from each sural nerve. Electron micrographs of cross-sectioned fibres with a magnification of 27,420 times were used to examine the relationship between the natural logarithm of the axonal area and the number of myelin lamellae. This relationship decreases with axonal atrophy. Axonal degeneration was assessed from teased fibre preparations and expressed as a percentage of total fibres.

Abnormalities of the node of Ranvier were examined by scoring of teased fibres exhibiting paranodal swelling, paranodal demyelination, and intercalated nodes. All teased fibre abnormalities as well as fibres exhibiting a normal morphology were examined from $106 \pm 2$

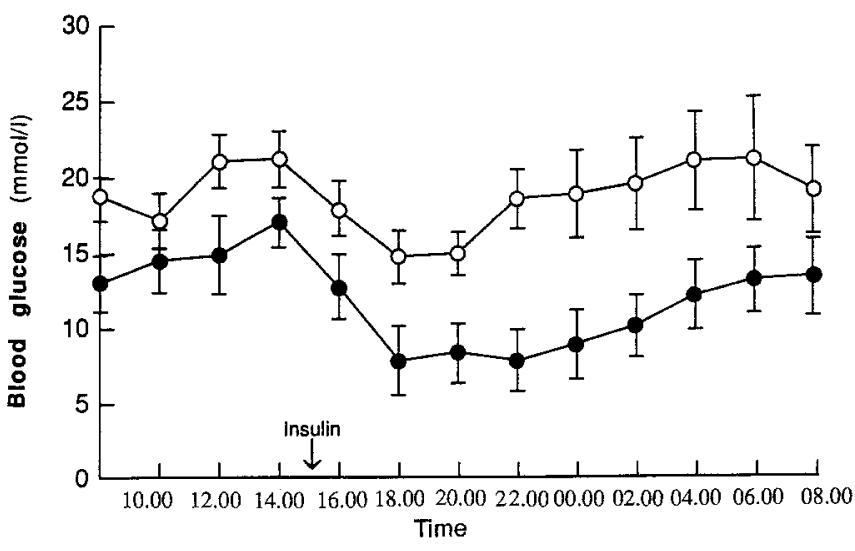

Fig. 1. The means of 2-h blood glucose levels in six non-treated and six acarbose-treated diabetic BB/W-rats are compared. The data was obtained from four 24-h cycles, hence each data point represents 24 examinations. Acarbose-treated diabetic rats demonstrate a significant reduction in the postprandial glucose levels, most marked during the night hours. The total reduction in glucose area was $40 \%$. Open circles $(O)$ represent non-treated diabetic rats and closed circles ( ) acarbose-treated diabetic rats 


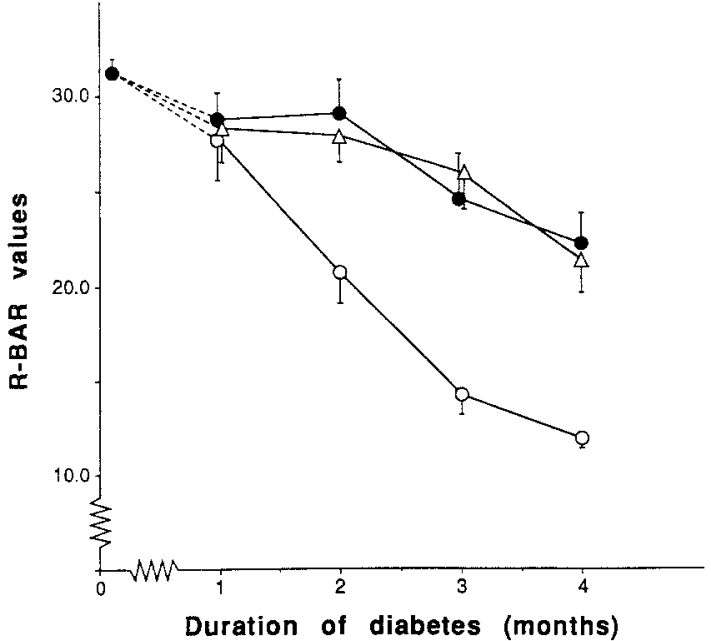

Fig. 2. R-BAR values in non-treated diabetic rats show a significant progressive decrease after onset of diabetes. This decrease was completely prevented by acarbose-treatment of diabetic BB/W-rats. Triangles $(\Delta)$ represent control rats, open circles $(O)$ diabetic rats, and closed circles $(\bullet)$ represent acarbose-treated diabetic rats

teased fibres per nerve and expressed as a percentage of the total number of teased fibres as previously described $[18,26]$. The frequency of axo-glial dysjunction was examined electron microscopically from a mean of $276 \pm 14$ terminal myelin loops per nerve. The frequency of myelin loops devoid of axo-glial junctions (axo-glial dysjunction) was expressed as a percentage of the total myelin loops [17].

\section{Statistical analysis}

Data are expressed as means \pm SEM. The significance of differences was calculated using Student's paired $t$-test.

\section{Results}

\section{Clinical findings}

Non-treated diabetic rats showed the characteristic decline in body weight gain. Acarbose-treated diabetic rats showed a body weight gain that was not significantly different from that of non-treated diabetic rats (Table 1). Both acarbose-treated and non-treated diabetic rats demonstrated polyuria $(>30 \mathrm{ml} / 24 \mathrm{~h})$ and glucosuria $(>2 \mathrm{~g} / 100 \mathrm{ml})$. In contrast non-diabetic control rats showed a 24-h urinary output of less than $5 \mathrm{ml}$ and no glucosuria. The insulin requirements of non-treated and acarbose-treated diabetic rats were similar $(1.72 \pm 0.06$ $\mathrm{U} /$ day vs $1.62 \pm 0.08 \mathrm{U} /$ day).

Weekly blood glucose levels measured at 15.00 hours were similarly increased in both non-treated and acarbosetreated diabetic rats compared to non-diabetic control rats (Table 1). However, when blood glucose levels were monitored over 24-h periods, a marked difference emerged between non-treated and acarbose-treated rats, the latter showing a $40 \%$ reduction in the 24 -h glucose area (Fig. 1 ). This reduction in blood glucose levels was most marked during the postprandial night hours and was reflected in lower glycated haemoglobin levels in acarbose-treated diabetic rats compared to non-treated diabetic rats (Table 1). The daily food intake was similar in acarbose treated (37.6 g/day) and non-treated diabetic rats ( $39.2 \mathrm{~g} /$ day), whereas non-diabetic control rats consumed somewhat less ( $33.8 \mathrm{~g} /$ day). Acarbose was well tolerated and treated rats only occasionally showed loose stools.

\section{$R$-BAR monitoring}

The vagal autonomic neuropathy in the diabetic BB/Wrat is characterized by a progressive decrease in R-BAR values, which precedes and accompanies the development of structural abnormalities [16]. Four months of untreated diabetes showed a progressive decline in R-BAR-values to $56 \%$ of normal values (Fig. 2). Acarbose-treated animals showed a significant $(p<0.001)$ and complete prevention of this decrease, suggesting that suppression of postprandial hyperglycaemia had a protective effect on the development of autonomic neuropathy.

\section{NCV monitoring}

Non-treated diabetic BB/W-rats showed the characteristic decrease in NCV over the 4-month observation period (Fig.3). A similar but milder NCV deficit was noted in acarbose-treated rats which showed significantly faster NCV's at months 1,2 , and $3(p<0.001)$ but not after 4 months of treatment (Fig. 3 ).

\section{Axonal structural changes}

Mean myelinated fibre size was significantly decreased in non-treated diabetic rats $(p<0.05$; Table 2$)$. No protective effect on myelinated fibre size could be demonstrated following acarbose treatment (Table 2). Fibre density and occupancy showed no change in untreated or acarbose-

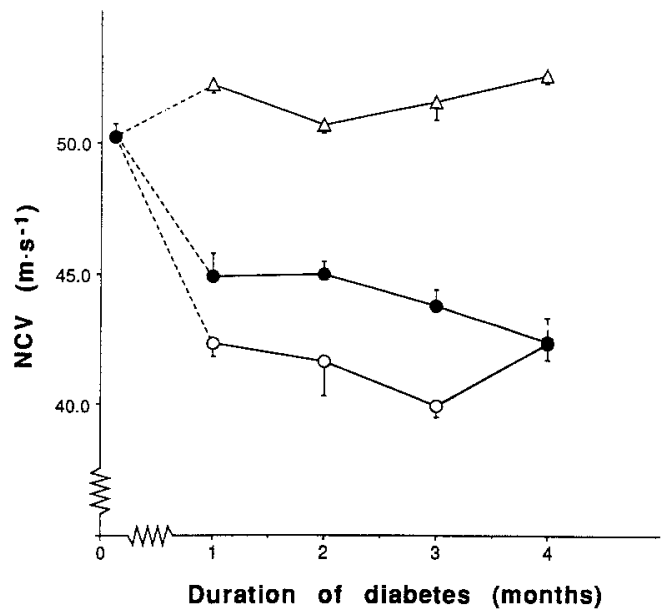

Fig. 3. Nerve conduction velocities (NCV) in control, diabetic and acarbose-treated diabetic rats. Acarbose treatment had a partial preventive effect on NCV for 3 months $(p<0.001)$ but it did not persist at 4 months of diabetes. Triangles $(\Delta)$ represent control rats, open circles $(O)$ diabetic rats, and closed circles $(\bullet)$ represent acarbose-treated diabetic rats 
Table 2. Comparisons of axonal changes between control, diabetic, and acarbose-treated $\mathrm{BB} / \mathrm{W}$-rats at the termination of the study protocol

\begin{tabular}{llll}
\hline & $\begin{array}{l}\text { Mean fibre size } \\
\left(\mu \mathrm{m}^{2}\right)\end{array}$ & $\begin{array}{l}\text { Wallerian de- } \\
\text { generation } \\
(\%)\end{array}$ & $\begin{array}{l}\text { Fibre re- } \\
\text { generation } \\
(\%)\end{array}$ \\
\hline $\begin{array}{l}\text { Control rats } \\
(n=6)\end{array}$ & $38.1 \pm 0.8$ & $0.5 \pm 0.3$ & $0.2 \pm 0.2$ \\
$\begin{array}{l}\text { Diabetic rats } \\
(n=6)\end{array}$ & $34.8 \pm 0.6^{\mathrm{a}}$ & $3.8 \pm 0.6^{\mathrm{b}}$ & $4.6 \pm 0.2^{\mathrm{c}}$ \\
$\begin{array}{l}\text { Acarbose treated } \\
\begin{array}{l}\text { Diabetic rats } \\
(n=6)\end{array}\end{array}$ & $35.6 \pm 1.4$ & $2.4 \pm 0.6^{\mathrm{b}}$ & $6.9 \pm 0.2^{\mathrm{c}, \mathrm{d}}$ \\
$\begin{array}{l}{ }^{\mathrm{a}} p<0.005,{ }^{\mathrm{b}} p<0.02,{ }^{\mathrm{c}} p<0.001 \text { vs control rats; }{ }^{\mathrm{d}} p<0.001 \mathrm{vs} \\
\text { diabetic rats }\end{array}$
\end{tabular}

Table 3. Normality and teased fibre changes of the node of Ranvier are compared in control, diabetic, and acarbose-treated BB/W-rats

\begin{tabular}{lllll}
\hline & $\begin{array}{l}\text { Normal } \\
\text { fibres } \\
(\%)\end{array}$ & $\begin{array}{l}\text { Paranodal } \\
\text { swelling } \\
(\%)\end{array}$ & $\begin{array}{l}\text { Paranodal } \\
\text { demyelination } \\
(\%)\end{array}$ & $\begin{array}{l}\text { Intercalated } \\
\text { nodes } \\
(\%)\end{array}$ \\
\hline $\begin{array}{l}\text { Control rats } \\
(n=6)\end{array}$ & $97.6 \pm 0.4$ & $0.4 \pm 0.2$ & $0.4 \pm 0.2$ & 0 \\
$\begin{array}{l}\text { Diabetic rats } \\
(n=6)\end{array}$ & $61.0 \pm 1.2^{\mathrm{a}}$ & $6.8 \pm 0.4^{\mathrm{a}}$ & $6.2 \pm 0.5^{\mathrm{a}}$ & $1.6 \pm 0.2^{\mathrm{b}}$ \\
$\begin{array}{l}\text { Acarbose treated } \\
\begin{array}{l}\text { Diabetic rats } \\
(n=6)\end{array}\end{array}$ \\
$\begin{array}{l}{ }^{\mathrm{a}} p<0.001,{ }^{\mathrm{b}} p<0.005 \text { vs control rats; }{ }^{\mathrm{c}} p<0.001,{ }^{\mathrm{d}} p<0.02 \mathrm{vs} \\
\text { diabetic rats }\end{array}$
\end{tabular}

treated $\mathrm{BB} / \mathrm{W}$-rats when compared to non-diabetic control rats (data not shown). More sensitive measurements of axonal atrophy such as excessive wrinkling of myelinated fibres in teased fibre preparations (Fig. 4) and axonmyelin ratio (Fig.5), showed significant axonal atrophy in non-treated diabetic rats which was significantly but incompletely prevented by acarbose treatment (Figs. 4 and 5). Wallerian degeneration was not affected by acarbose treatment (Table 2), whereas the frequency of regenerating fibres was significantly increased $(p<0.001)$ following acarbose treatment (Table 2).

\section{Nodal changes}

Both human [18] and murine diabetes [12] are characterized by a sequence of nodal neuroanatomical abnormalities consisting of paranodal swelling, axo-glial dysjunction, paranodal demyelination, and remyelinated, so called intercalated nodes. These sequential changes were all significantly increased in non-treated diabetic rats (Table 3), and with the exception of axo-glial dysjunction were all completely prevented by acarbose treatment. Although the frequency of axo-glial dysjunction was decreased by almost $40 \%$ (Fig. 6) following acarbose treatment, it was not completely prevented by lowering of postprandial hyperglycaemia.

\section{Discussion}

Acarbose is a pseudotetrasaccharide that acts as a competitive inhibitor of pancreatic $\alpha$-amylase and several intestinal $\alpha$-glucosidases but with a particular affinity for sucrase. When given orally together with carbohydrates it prevents glucose uptake and decreases the postprandial increase in blood glucose $[21,23,24]$. The remaining unabsorbed carbohydrates are degraded by microorganisms in the large bowel. As expected from the action of acarbose, the present study resulted in a substantial decrease of postprandial hyperglycaemia that was reflected by a $40 \%$ reduction of the 24-h glucose area. It is therefore likely that long-term treatment with this compound will decrease the magnitude of cumulative hyperglycaemia believed to be a major risk factor in the development of secondary diabetic complications [2,3]. In keeping with this notion, previous studies on the effect of acarbose have demonstrated decreased glomerular mesangial expansion and reduced deposition of glomerular immunoglobulins in kidneys of diabetic $\mathrm{db} / \mathrm{db}$ mice [27]. Acarbose also reduces non-enzymatic glycation and the formation of advanced glycation end products in extracellular matrices such as the glomerular basement membrane [28].

Diabetic neuropathies are believed to be initiated by hyperglycaemia and its effect on the polyol pathway leading to secondary abnormalities of myo-inositol metabolism and $\mathrm{Na} / \mathrm{K}$-ATP-ase activity in peripheral nerve $[2,7]$. We have previously demonstrated that interventions aimed at correcting various steps of this cascade of metabolic abnormalities in the $\mathrm{BB} / \mathrm{W}$-rat result in acute normalization of biochemical and functional abnormalities $[26,29,30]$, and in long-term studies prevention of structural abnormalities $[31,32]$. These interventions have included normalization of hyperglycaemia with vigorous insulin therapy, aldose reductase inhibition with normalization of the polyol pathway as well as myo-inositol supplementation.

In the present study the reduction of the total glucose load on peripheral nerve, achieved mainly by lowering the

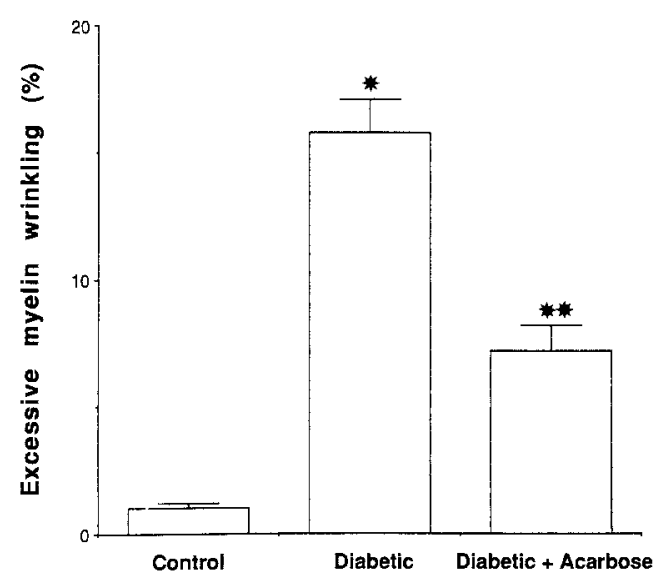

Fig. 4. The frequency of excessive myelin wrinkling, a measure of the extent of axonal atrophy, is compared in control, diabetic, and acarbose-treated diabetic rats. Acarbose treatment resulted in a significant $55 \%$ reduction of excessive myelin wrinkling $* p<0.001$ vs control and acarbose-treated rats; and $* * p<0.001$ vs diabetic rats 


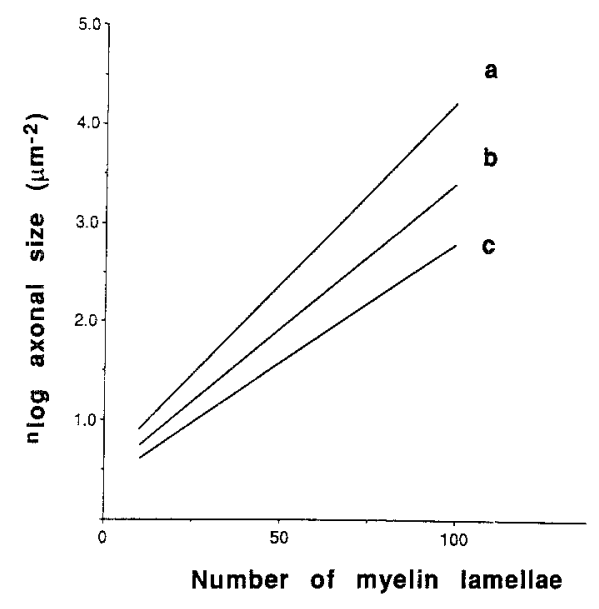

Fig.5. Acarbose-treated diabetic rats (b) showed a significant but partial $(p<0.05)$ prevention of the characteristic decrease in axon/myelin ratio compared to diabetic rats (c) indicating a less severe axonal atrophy. However, both acarbose-treated (b), and diabetic rats (c) showed lower axon-myelin ratios than control rats (a) $(p<0.005$ and $p<0.001$ respectively)

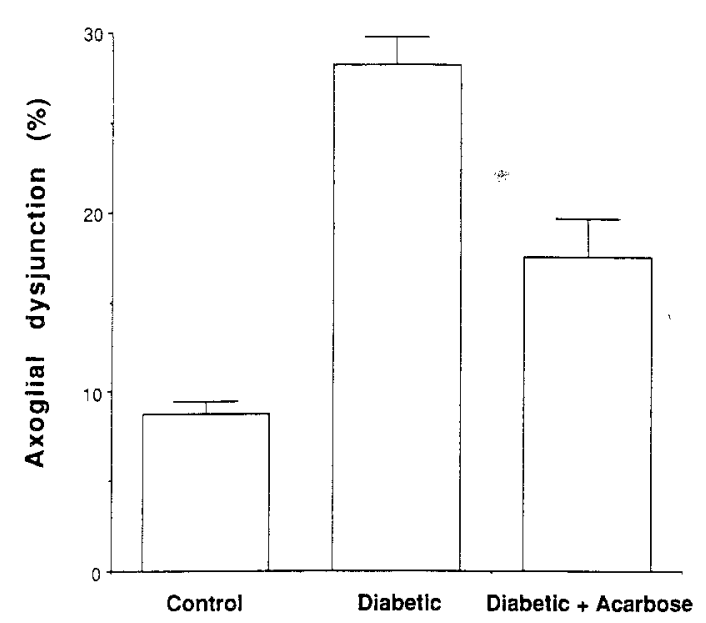

Fig. 6. Axo-glial dysjunction, a characteristic lesion of the paranodal region was partially but significantly $(p<0.005)$ prevented by acarbose treatment. Compared to control rats axo-glial dysjunction was significantly increased $(p<0.001)$ in both diabetic and acarbosetreated diabetic rats

hyperglycaemic peak during postprandial night hours, resulted in similar effects as those previously described. Although the affinity of aldose reductase, the key enzyme in the polyol pathway, is low for glucose, the level of hyperglycaemia in the non-treated BB/W-rat is sufficient to significantly increase the concentration and the activity of the aldose reductate enzyme and to enhance polyol pathway activity [33]. The lowering of cumulative hyperglycaemia in the present study, particularly the reduction of the night hours' peaks, may therefore be sufficient to substantially reduce the activity of the polyol pathway and therefore prevent autonomic polyneuropathy and attenuate the development of somatic polyneuropathy in the $\mathrm{BB} / \mathrm{W}$-rat. The autonomic polyneuropathy in the $\mathrm{BB} / \mathrm{W}$ rat characterized by decreased R-BAR-values, was completely prevented by 4 months of acarbose treatment and the somatic polyneuropathy identified by slowed NCV and characteristic neuroanatomical abnormalities was partially prevented by the same regimen. This discrepancy in the effect of acarbose on autonomic vs somatic polyneuropathy in the $\mathrm{BB} / \mathrm{W}$-rat is consistent with development of somatic polyneuropathy more easily compared to autonomic polyneuropathy under similar hyperglycaemic conditions in this animal model [12].

Axonal atrophy, a characteristic lesion of both murine and human diabetic somatic polyneuropathy $[13,19,20]$, was markedly but incompletely prevented by acarbose. This is in agreement with a complete prevention of axonal atrophy following long-term treatment with an aldose reductase inhibitor in the BB/W-rat and a significant improvement of axonal atrophy in human diabetic neuropathy following 18 months of aldose reductase inhibitor treatment $[31,33,34]$. Similarly the increase in the frequency of regenerating fibres in acarbose-treated rats parallels the findings following other modes of metabolic correction of the diabetic nerve $[31,32]$, suggesting that the consequences of hyperglycaemia deprives the diabetic nerve of its regenerative capacity.

In conclusion, the present study has demonstrated that acarbose effectively reduces postprandial hyperglycaemia in the spontaneously diabetic BB/W-rat, and that this effect retards the development of diabetic neuropathy in this animal model, indicating that the magnitude of cumulative hyperglycaemia is a major factor in the development of diabetic neuropathies.

Acknowledgements. This study was supported in part by grants from Miles, Inc., New Haven, Connecticut, USA, the Canadian Medical Research Council (MT-10673, MA-10674) and National Institutes of Health (DK-38304). The authors are indebted to Ms. E. Moore for preparing the manuscript.

\section{References}

1. Melton LJ, Dyck PJ (1987) Epidemiology. In: Dyck PJ, Thomas PK, Asbury AK, Winegrad AI, Porte D Jr (eds) Diabetic neuropathy. WB Saunders, Philadelphia, pp 27-35

2. Greene DA, Sima AAF, Albers JW, Pfeifer M (1989) Diabetic neuropathy. In: Rifkin H, Porte D (eds) Ellenberg and Rifkin, Diabetes mellitus. Elsevier, New York, pp 710-755

3. Pirart J (1978) Diabetes mellitus and its degenerative complications: a prospective study of 4,400 patients observed between 1947 and 1973. Diab Care 1: 168-188

4. Johnson PC, Doll SC, Cromey DW (1986) Pathogenesis of diabetic neuropathy. Ann Neurol 19: 450-457

5. Winegrad AI, Simmons DA, Martin DB (1983) Has one diabetic complication been explained? N Engl J Med 308: 152-154

6. Winegrad AI (1987) Does a common mechanism induce the diverse complications of diabetes? Diabetes $36: 396-406$

7. Greene DA, Lattimer SA, Sima AAF (1987) Sorbitol, phosphoinositides and sodium-potassium-ATPase in the pathogenesis of diabetic complications. N Engl J Med 316: 599-606

8. Dyck PJ, Karnes JL, O’Brien P, Okazaki H, Lais A, Engelstad J (1986) The spatial distribution of fiber loss in diabetic polyneuropathy suggests ischemia. Ann Neurol 19: 440 444

9. Sima AAF, Nathaniel V, Prashar A, Bril V, Greene DA (1991) Endoneurial microvessels in human diabetic neuropathy: endothelial cell dysjunction and lack of treatment effect by aldose reductase inhibitor. Diabetes 40: 1090-1099 
10. The DCCT Research Group (1988) Factors in the development of diabetic neuropathy: baseline analysis of neuropathy in feasibility phase of diabetes control and complications trial (DCCT). Diabetes 37: 476-481

11. Maser RE, Steenkiste AR, Dorman JS et al. (1989) Epidemiological correlates of diabetic neuropathy. Report from Pittsburgh Epidemiology of Diabetes Complications Study. Diabetes 38: $1456-1461$

12. Sima AAF (1985) Can the BB-rat help to unravel diabetic neuropathy? Neuropath Appl Neurobiol 11:253-264

13. Sima AAF, Bouchier M, Christensen H (1983) Axonal atrophy in sensory nerves of the diabetic BB-Wistar rat: a possible early correlate of human diabetic neuropathy. Ann Neurol 14: 183-188

14. Sima AAF (1983) The development and structural characterization of the neuropathies in the BB-Wistar rat. Metabolism 32 [Suppl 1]: 106-111

15. McEwen TAJ, Sima AAF (1987) Autonomic neuropathy in the BB-rat. Assessment by an improved method for measuring heart rate variability. Diabetes $36: 251-255$

16. Zhang WX, Chakrabarti S, Greene DA, Sima AAF (1990) Diabetic autonomic neuropathy in BB-rats: the effect of ARItreatment on heart rate variability and vagus nerve structure. Diabetes 39: 613-618

17. Sima AAF, Lattimer SA, Yagihashi S, Greene DA (1986) Axoglial dysjunction: a novel structural lesion that accounts for poorly reversible slowing of nerve conduction in the spontaneously diabetic BB-rat. J Clin Invest 77: 474-484

18. Sima AAF, Nathaniel V, Bril V, McEwen TAJ, Greene DA (1988) Histopathological heterogeneity of neuropathy in insulindependent and non-insulin-dependent diabetes and demonstration of axo-glial dysjunction in human diabetic neuropathy. J Clin Invest $81: 349-364$

19. Bischoff A (1968) Diabetische neuropathie. Dtsch Med Wochenschr 93: 237-241

20. Yagihashi S, Matsumaja M (1979) Ultrastructural pathology of peripheral nerves in patients with diabetic neuropathy. Tohoku $\mathrm{J}$ Exp Med 129: 357-366

21. Gray RS, Olefsky JM (1982) Effect of glucosidase inhibitor on the metabolic response of diabetic rats to a high carbohydrate diet consisting of starch and sucrose, or glucose. Metabolism 31: $88-92$

22. Yamashita K, Sugawara S, Sakairi I (1984) Effects of an alphaglucosidase inhibitor, Acarbose, on blood glucose and serum lipids in streptozotocin-induced diabetic rats. Horm Metab Res 16: $179-182$

23. Madariaga H, Lee PC, Heitlinger LA, Libenthal E (1988) Effects of graded $\alpha$-glucosidase inhibition on sugar absorption in vivo. Digest Dis Sci 33: 1020-1024

24. Hillebrand I, Boehm K, Graefe KH, Wehling K (1986) The effect of new $\alpha$-glucosidase inhibitors (BAY in 1099 and BAY o 1248) on meal-stimulated increases in glucose and insulin levels in man. Klin Wochenschr 64: 393-396
25. McEwen TAJ, Sima AAF (1989) Microcomputer collection and analysis of RR-interval data in the BB-rat. Comput Biol Med 19: $443-452$

26. Greene DA, Chakrabarti S, Lattimer SA, Sima AAF (1987) Role of sorbitol accumulation and myoinositol depletion in paranodal swelling of large myelinated nerve fibres in the insulindeficient spontaneously diabetic biobreeding rat. J Clin Invest 79: 1479-1485

27. Lee SM (1982) The effect of chronic alpha-glucosidase inhibition of diabetic nephropathy in the $\mathrm{db} / \mathrm{db}$ mouse. Diabetes 31: 249 254

28. Cohen MP (1991) Acarbose inhibits excess nonenzymatic glycation of extracellular matrices. In: Shafrir E (ed) Frontiers in diabetes research. Lessons from animal diabetes III. Smith-Gordon, London, pp 417-420

29. Sima AAF, Brismar R (1985) Reversible diabetic nerve dysfunction. Structural correlates to electrophysiological abnormalities. Ann Neurol 18: 21-29

30. Brismar T, Sima AAF, Greene DA (1987) Reversible and irreversible nodal dysfunction in diabetic neuropathy. Ann Neurol 21: 504-507

31. Sima AAF, Prashar A, Zhang WX, Chakrabarti S, Greene DA (1990) The preventive effect of long term aldose reductase inhibition (Ponalrestat) on nerve conduction and sural nerve structure in the spontaneously diabetic BB-rat. J Clin Invest 85: 1410 1420

32. Lattimer SA, Chakrabarti S, Greene DA, Sima AAF (1991) Metabolic correction with myoinositol retards the development of chronic diabetic neuropathy in the BB-rat. Diabetes 40: $267 \mathrm{~A}$ (Abstract)

33. Ghahary A, Chakrabarti S, Sima AAF, Murphy LJ (1991) The effect of insulin and statil on aldose reductase expression in the diabetic rat. Diabetes 40: 1391-1396

34. Sima AAF, Greene DA (1991) Correlations between nerve morphometry, electrophysiology and sensory score in diabetic neuropathy, and their implications for the design of aldose reductase clinical neuropathy trials. US-Japan Aldose Reductase Workshop, Kona (Abstract)

Received: 18 September 1991

and in revised form: 27 November 1991

Prof. A. A. F.Sima

Michigan Diabetes Research and Training Center

The University of Michigan

1331 East Ann Street

Box 0580

Ann Arbor, MI 48109

USA 